\title{
RETRACTED ARTICLE: Sperm DNA damage due to the oxidative stress associated with varicocele
}

Emad Mustafa Siam • Mohamed Tawfeek •

Momen Hassan

Received: 4 November 2010 / Accepted: 21 December 2010/Publishedonline:13January2011

(C) Springer Science+Business Media, LLC 2011

This article has been published OnlineFirst, but is withdrawn due to the charges of plagiarism derived from the detection of multiple statements and figures, which were identical to those published in a 2006 paper by Dr. Smith and his colleagues in the journal Human Reproduction.

E. M. Siam $(\bowtie) \cdot$ M. Tawfeek $\cdot$ M. Hassan

Department of Obstetrics and Gynecology, College of Medicine,

El-Minya University Hospital,

El-Minya, Egypt

e-mail: eemsalah@yahoo.com 